\title{
Nucleus Accumbens and Posterior Amygdala Mediate Cue-Triggered Alcohol Seeking and Suppress Behavior During the Omission of Alcohol-Predictive Cues
}

\author{
E Zayra Millan*,', Rebecca M Reese', Cooper D Grossman', Nadia Chaudhri ${ }^{2}$ and Patricia H Janak' \\ 'Department of Psychological and Brain Sciences, Johns Hopkins University, Baltimore, MD, USA; ' Center for Studies in Behavioural Neurobiology/ \\ Groupe de recherche en neurobiologie comportementale, Department of Psychology, Concordia University, Montreal, Quebec, Canada
}

\begin{abstract}
Neurobiological mechanisms that influence behavior in the presence of alcohol-associated stimuli involve processes that organize behavior during the presence of these cues, and separately, regulation of behavior in their absence. However, little is known about anatomical structures that might mediate this regulation. Here we examined nucleus accumbens shell (AcbSh) as a possible neural substrate mediating behavior modulation triggered by the presence and absence of alcohol-associated environmental cues and contexts. We also examined subregions of basal amygdala nuclei - rostral basolateral (BLA) and basal posterior (BAP) - as they provide a major source of glutamatergic input to the AcbSh. Animals were trained to associate an auditory conditioning stimulus with alcohol in a discriminative context and then subsequently tested for conditioned port-entries across contexts either previously associated or not associated with alcohol. We found that, on test to the alcohol cue alone, AcbSh inactivation prevented conditioned port-entries in contexts that either were associated with alcohol or were novel, while also increasing unconditioned port-entries during the intertrial intervals. When tested to alcohol-reinforced cues, AcbSh inactivation produced more cue-trial omissions and elevated unconditioned port-entries. Interestingly, BLA and BAP inactivation produced dissociable effects. BAP but not BLA increased unconditioned port-entries, while both manipulations prevented conditioned port-entries during the alcohol-cue. We conclude that AcbSh is necessary for modulating control over behavior otherwise guided by the presence of alcohol-predictive environmental stimuli and contexts. Moreover, this role may involve integration of functionally segregated inputs from rostral and posterior portions of basal amygdala nuclei.

Neuropsychopharmacology (20I5) 40, 2555-2565; doi:I0.I038/npp.20I5.I02; published online I3 May 2015
\end{abstract}

\section{INTRODUCTION}

Behavior guided by drug-predictive cues relies on adapting performance in the presence and absence of relevant cues. The neural substrates that modulate these shifts are not well-characterized, although they may have a critical role in facilitating control over alcohol use. Accumulating evidence, primarily from instrumental self-administration models, suggests that AcbSh actively inhibits non-rewarded behavior. For example, AcbSh maintains extinction of cocaine- and alcohol-seeking (Millan et al, 2010; Peters et al, 2008; Sutton et al, 2003) and reduces lever pressing for food in the presence of non-reinforced cues (Ambroggi et al, 2011). Moreover, in vivo recording studies suggest that AcbSh neurons differentially respond to rewarded and nonrewarded behaviors. For example, sucrose-predictive cues and bouts of sucrose licking are both associated with

\footnotetext{
*Correspondence: Dr EZ Millan, Department of Psychological and Brain Sciences, Johns Hopkins University, 3400 N. Charles Street, Dunning Hall, room 224, Baltimore, MD 21218, USA, Tel: + 7074003135 , Fax: + 410516 0494, E-mail: ezmillan@jhu.edu

Received 16 December 2014; revised 10 March 2015; accepted 16 March 2015; accepted article preview online 15 April 2015
}

inhibition of AcbSh neurons (Krause et al, 2010; Roitman et al, 2005). Conversely, increases in basal firing of medial Acb neurons are associated with inhibition of lever pressing during a reward omission cue and ambulation away from a drug-paired chamber (German and Fields, 2007; Ghazizadeh et al, 2012). Finally, AcbSh electrical or deep brain stimulation inhibits reward-associated behaviors including sucrose licking and cocaine-primed reinstatement (Krause et al, 2010; Vassoler et al, 2013). However, AcbSh is also necessary for the performance of several reward-reinforced behaviors; AcbSh lesions or inactivations disrupt the potentiating effect of Pavlovian conditioned cues on instrumental behavior (Corbit et al, 2001), conditioned approach during a sucrose-reinforced cue (Blaiss and Janak, 2009), and context-induced reinstatement of drug seeking (Cruz et al, 2014). Thus, AcbSh can serve both to inhibit behavior and to promote the behavioral impact of context- or cue-reward associations. Dissociating or integrating these AcbSh properties has important implications for neuropsychopharmacological studies seeking to target specific AcbSh-dependent processes involved in drug-seeking.

Here we investigated the inhibitive and promotive influence of AcbSh over Pavlovian conditioned behavior to 
alcohol-predictive cues across alcohol- and non-alcoholassociated contexts. We predicted that pharmacological inhibition of AcbSh would produce composite effects: attenuating and augmenting behavior depending on the presence or absence of the alcohol cue, respectively. We used contexts as a means to probe whether these distinct effects of AcbSh inactivation were dissociable. If so, disinhibition of behavior during the absence of the cue should occur following AcbSh inactivation across all contexts, whereas previous work (Chaudhri et al, 2010) suggests that alcoholcue conditioned behavior may be attenuated in specifically an alcohol-associated context.

As the Acb receives significant innervation from basolateral amygdala (BLA) (Brog et al, 1993; McDonald, 1991), the AcbSh is likely influenced by amygdala-encoded reward-cue information. As one example, contralateral disconnection of BLA from AcbSh prevented cues from biasing instrumental behavior in Pavlovian-to-instrumental transfer (Shiflett and Balleine, 2010). However, the medial AcbSh is also innervated by other amygdala nuclei, in particular, by posterior basal amygdala nucleus (BAP) (Canteras et al, 1992; Thompson and Swanson, 2010). Unlike rostral BLA, BAP is positioned within the main olfactory cortex system (Petrovich et al, 2001). As a consequence, BAP, like AcbSh, accesses lateral hypothalamic function directly (Petrovich et al, 2001). An intriguing possibility is that BAP and AcbSh may share a similar role in regulating reward-cue behaviors. Although much less is known of the function of BAP relative to anterior BLA, studies suggest that posterior and rostral amygdala are functionally dissociable on reinstatement tests (Kantak et al, 2002; McLaughlin and Floresco, 2007). Anatomically, BAP and BLA have topographically segregated projections to AcbSh: BAP innervation is restricted to the AcbSh dorsomedial tip, whereas BLA broadly innervates both core and shell subregions (Canteras et al, 1992; Cho et al, 2013; McDonald, 1991). Intriguingly, lateral hypothalamus-projecting neurons from AcbSh dorsomedial tip are engaged during suppression of alcohol seeking following extinction (Marchant et al, 2009). Thus, AcbSh is uniquely positioned to influence behavior via integration of information from separately organized amygdala systems, noting that BAP and BLA (rostral) are not themselves directly connected (Canteras et al, 1992). We therefore examined the functional contributions of BLA and BAP over cue-driven alcohol seeking, hypothesizing that their roles were dissociable and that BAP and AcbSh might share similar functional properties.

\section{MATERIALS AND METHODS}

\section{Behavior}

Subjects. Experimentally naive male Long-Evans rats (Harlan, IN; 200-215 g) were individually housed in ventilated polycarbonate cages in a temperature $\left(21^{\circ} \mathrm{C}\right)$ and light-regulated vivarium (lights on 0700 hours, $12 \mathrm{~h}$ light/dark cycle) with partial enrichment. Food and water were freely available throughout these studies. All procedures were approved by the institutional animal care and use committee, and concur with recommendations in the Guide for the Care and Use of Laboratory Animals (Institute of
Laboratory Animal Resources, Commission of Life Sciences, National Research Council, 1996).

Intermittent EtOH homecage exposure. Before behavioral training, rats were acclimated to the taste and pharmacological effects of EtOH. They received 10-11 days of homecage access to EtOH $(15 \% \mathrm{v} / \mathrm{v})$ on a chronic intermittent schedule (Remedios et al, 2014; Simms et al, 2008). In brief, two-bottle access to EtOH and water in the homecage occurred on Monday, Wednesday, and Friday, while only water was available on remaining days. Rats were handled daily, and values for rat and bottle weight changes were recorded. Rats with ethanol intake $<1 \mathrm{~g} / \mathrm{kg}$ were excluded. Mean \pm SEM ethanol intake $(\mathrm{g} / \mathrm{kg}$ ) across the last 2 days of homecage access were $4.49 \pm 0.42$ (Experiment 1 : AcbSh); $4.48 \pm 0.65$ (Experiment 2: BLA); and $4.02 \pm 0.65$ (Experiment 3: BAP).

Surgery and microinfusion procedure. Rats were anesthetized with isoflurane and implanted bilaterally with 26-gauge guide cannulae (Plastics One, Roanoke, VA) aimed at AcbSh (AP:+1.35; ML: \pm 0.75 ; DV: -6.5 ; with injector DV:7.5), BLA (AP: -2.8 ; ML: \pm 4.9 ; DV: -6.65 ; with injector DV:8.65), or BAP (AP: $-3.45 / 3.55 ; \quad$ ML: $\pm 5.0 / 4.8 ;$ DV: $-7.0 / 7.2$; with injector DV:8.5-8.7). Following recovery, rats received 2 days of intermittent homecage EtOH access. On test they received bilateral infusions $(0.5 \mu \mathrm{l} \mathrm{vol} ; 0.3 \mu \mathrm{l} / \mathrm{min})$ of saline (SAL) or a GABAB and GABAA agonist solution (baclofen hydrochloride, $1.0 \mathrm{~mm}$, and muscimol hydrobromide, $0.1 \mathrm{~mm}$; B/M; Sigma-Aldrich). After allowing an additional $2 \mathrm{~min}$ for diffusion, microinjectors (33 gauge) were removed and rats were returned to their home-cage for $\sim 5-10 \mathrm{~min}$ before test.

Apparatus and training: context-discrimination of Pavlovian conditioned EtOH cue. We used a context discrimination design to assess AcbSh and basal amygdala contributions to EtOH-predictive cues. This design, where animals receive cue-EtOH pairings in one of two equally trained contexts (detailed in Remedios et al, 2014), has the advantage of modulating the behavioral impact of an EtOH cue. That is, cue behavior is highest in an EtOH-associated context, and attenuated in a context paired with the absence of $\mathrm{EtOH}$ or associated cues. Thus, if neural inactivation disinhibits behavior broadly, we can assess disinhibition on cued behavior in the neutral context, which has a lower baseline for detecting possible potentiation of behavior. Moreover, we assessed whether an hypothesized inhibitory and promotive influence of AcbSh during conditioned behavior might be differentially affected by context. Behavior in a novel context is also assessed and provides additional assessment of conditioned behavior in an environment not associated with EtOH.

Rats were run 5 days a week in conditioning chambers (Med Associates, St Albans, VT). The first 2 days, rats received two 20-min port-training sessions each day with six $0.2-\mathrm{ml} \mathrm{EtOH}$ deliveries at a variable interval (VI) of $240 \mathrm{~s}$. Subsequently, they commenced 20-24 days of contextdiscrimination training. Rats were placed in one of two contexts, alternating each day, distinct in their chamber walls (black $v s$ clear), flooring (Perspex $v s$ mesh) and odor (lemon oil $v s$ benzaldehyde deposited in bedding tray corners) 
a

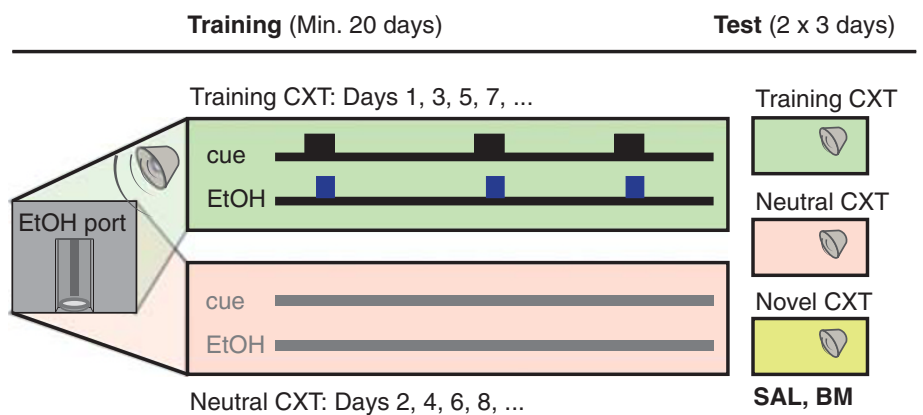

b

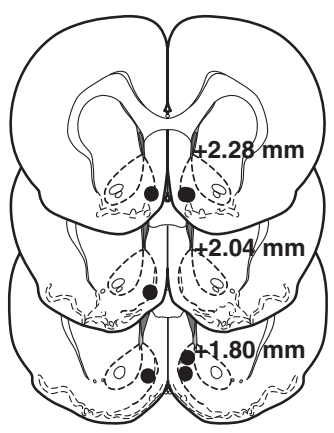

AcbSh

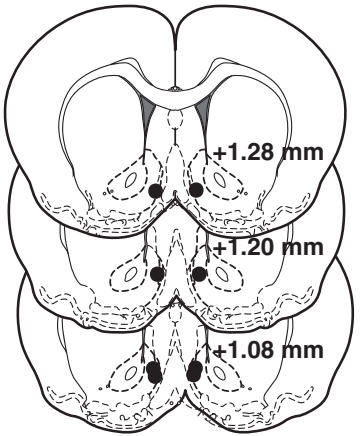

C

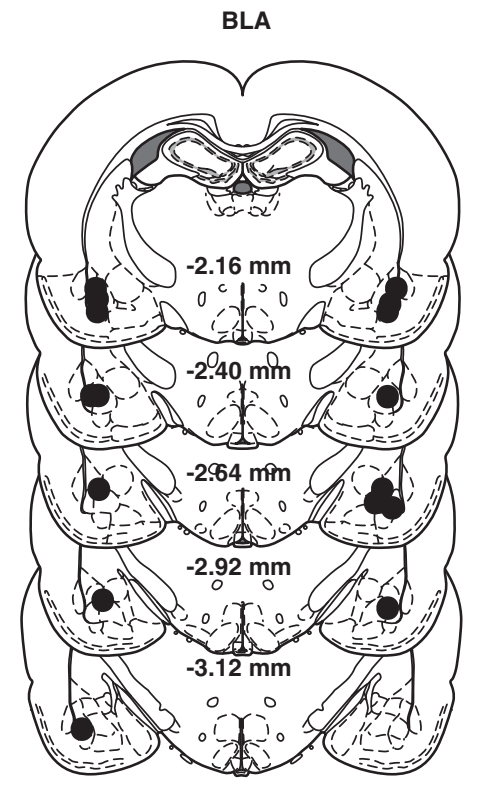

d

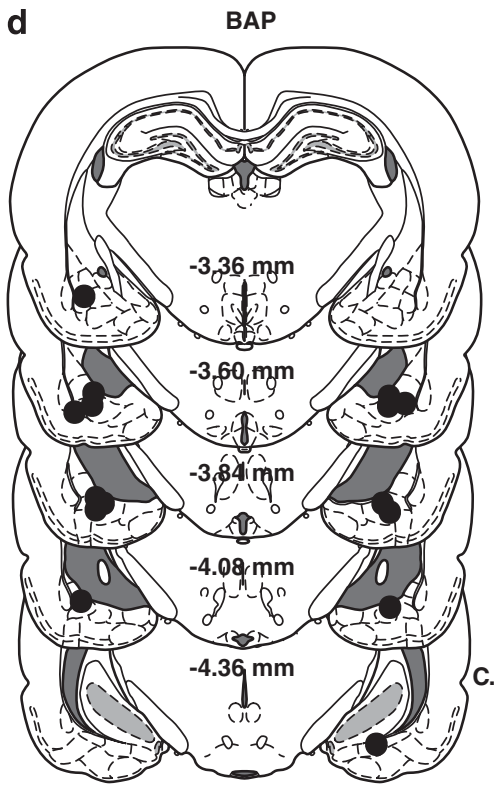

e excl. BAP

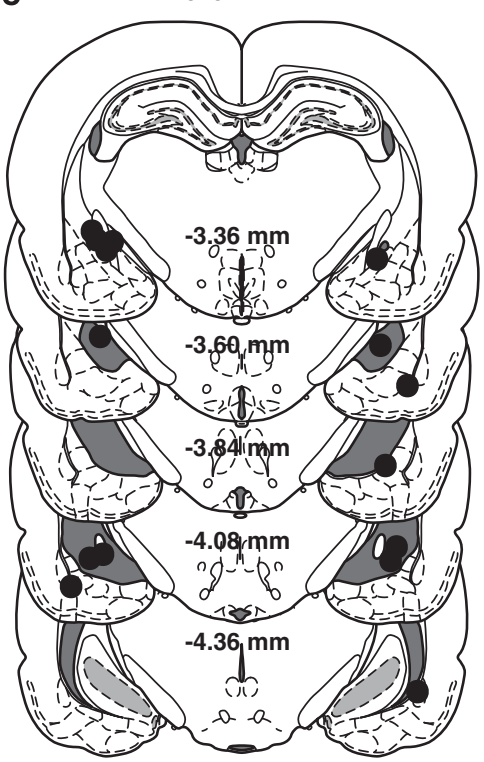

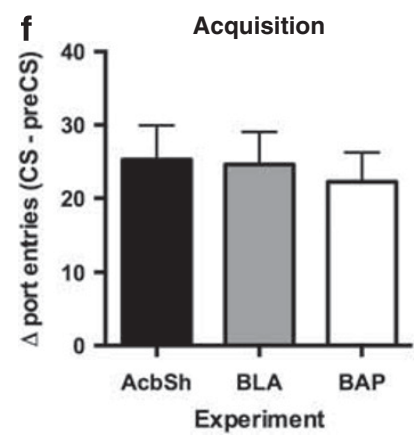

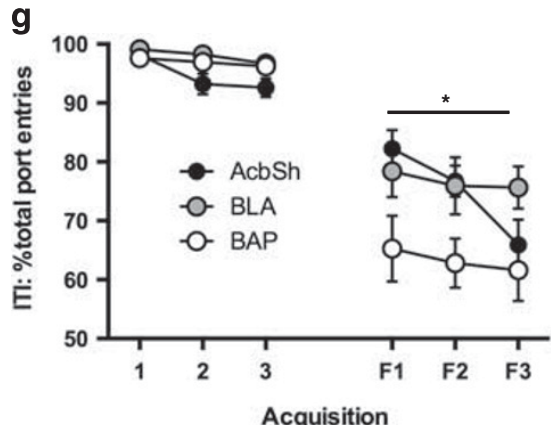

Figure I (a) Schematic diagram of the alcohol-cue discriminative context task. This task modulates the impact of the alcohol cue on behavior across discriminative contexts that previously were explicitly paired with the presence of cue + alcohol (training context) or absence of cue/alcohol (neutral context). A novel test context controls for arousing contextual properties dissociated from previous alcohol reinforcement history. (b-e) Placement of injector tips within AcbSh, BLA, BAP, and periBAP placements (animals excluded from BAP analysis). Placements are mapped onto coronal sections labeled with distance $(\mathrm{mm})$ from bregma. $(\mathrm{f})$ Mean $( \pm \mathrm{SEM})$ numbers of normalized cue port-entries averaged across the last two acquisition days for all experiments. (g) Mean $\left( \pm\right.$ SEM) portion of port-entries during ITI is higher during initial three than final three $(F I, F 2, F 3)$ days of acquisition for all experiments: AcbSh $\left(F_{(1.9)}=52.57\right.$, $p<0.05) ; \operatorname{BLA}\left(F_{(1.8)}=34.84, p<0.05\right) ;$ BAP $\left._{(1.7)}=83.47, p<0.05\right) ; * 00.05$.

described in Remedios et al (2014). As depicted in Figure 1a, one context served as the training context, wherein fifteen 10 -s cue presentations (white noise, $10-25 \mathrm{kHz}, 20 \mathrm{~dB}$ ) were each paired with $0.2 \mathrm{ml} \mathrm{EtOH} \mathrm{(15 \%} \mathrm{v/v)} \mathrm{delivered} \mathrm{into} \mathrm{a}$ receptacle (VI:240 s) recessed in one chamber wall. The other served as a neutral context, where neither cue nor EtOH was delivered. Thus, both contexts were equated in familiarity but different in training history.

Test: non-reinforced and reinforced EtOH cue. At the completion of training, rats were tested for responding to a non-reinforced $\mathrm{EtOH}$ cue to assess the motivational impact 
of the cue without influence from reinforcing, sensory, or pharmacological properties of the EtOH solution. Tests occurred across three contexts (training, neutral, and novel; Figure 1a) over consecutive days, followed by 4 days of context discrimination retraining, and subsequent nonreinforced re-testing in all contexts, with context order counterbalanced across rats. Rats were randomly allocated to receive SAL or $\mathrm{BM}$ for the first series of testing, and groups were reversed for the second. The novel context comprised striped or white wall covers, one of two odors (peppermint and strawberry or peppermint and banana), and grid flooring, and was altered per test session to maintain novelty.

Following the final non-reinforced test, rats in the AcbSh and BAP experiment received an additional 2 days retraining in the training context, followed by reinforced EtOH cue tests under both SAL and B/M (counter-balanced) in the training context.

\section{Histology}

Formalin-fixed $50-\mu \mathrm{m}$ coronal slices containing cannula tracts were collected onto glass slides, thionin-stained for Nissl substance and cover-slipped with DePeX mounting medium. Cannula tip placements in AcbSh $(N=10)$, BLA $(N=9)$ and BAP $(N=8)$ are shown in Figure $1 b-d$. Data from rats with misplaced BAP placements were analyzed independently as an anatomical control group (excl. BAP; $N=7$ ). Otherwise, subjects with misplaced cannulae or lesion damage were excluded (AcbSh: $N=5$; BLA: $N=4)$.

\section{Statistical Methods}

Number and time of port-entries were collected throughout training and test. Normalized cue behavior was measured as the total number of port-entries during the $\mathrm{EtOH}$ cue minus port-entries during a 10 -s pre-cue interval. Unconditioned behavior was measured as port-entries during the intertrial interval (ITI). ITI measurement excluded port-entries during the 10 -s post-cue interval to ensure that measured portentries did not include conditioned behavior. This adjustment appeared necessary, as in all non-reinforced tests reported here, port-entries during the 10-s post-cue interval was significantly elevated relative to the 10 -s pre-cue interval ( $p$-values $<0.05)$. Latencies to initiate cued portentries were also measured. All data were analyzed using planned orthogonal contrasts in a within-subjects multivariate ANOVA, and significance was assessed against a type I error rate of 0.05 .

\section{RESULTS}

We assessed the effects of neuronal inactivation of AcbSh, BLA, and BAP on conditioned alcohol cue-triggered behavior across contexts either previously associated or not associated with alcohol. In brief, the training context refers to a discriminative context where cue-EtOH associations were trained. The neutral and novel contexts have no previous history with $\mathrm{EtOH}$ or cues, but the former is equivalent to the training context in number of context exposures.

\section{Acquisition Training for Context Modulation of Cue-Triggered EtOH seeking-AcbSh, BLA, and BAP Inactivation}

Across acquisition, animals learned to enter a fluid port during presentation of a 10-s auditory cue. Six animals were excluded from the remainder of the study for failing to meet a criterion of a minimum average of 10 cued responses over the last 2 days of training (BLA, $n=2$; BAP, $n=4$ ). Across the last 2 days of training, port-entries during the cue were more frequent than port-entries during a 10 -s pre-CS interval for all experiments: AcbSh $\left(\mathrm{F}_{(1,9)}=29.73, p<0.05\right)$; BLA $\left(\mathrm{F}_{(1,8)}=30.88, p<0.05\right)$; $\operatorname{BAP}\left(\mathrm{F}_{(1,7)}=38.79, p<0.05\right)$. Moreover, receptacle ports at the end of these sessions were inspected to confirm that the total delivered $\mathrm{EtOH}(3 \mathrm{ml})$ was consumed for all subjects in this study. Mean $( \pm$ SEM) for $\mathrm{EtOH}$ consumed $(\mathrm{g} / \mathrm{kg})$ at the end of training were AcbSh, $0.77 \pm(.01) ;$ BLA, $0.84 \pm(.02) ;$ BAP, $0.81 \pm(.01)$. These values are similar to those reported previously with $15 \%$ $\mathrm{EtOH}$ (Remedios et al, 2014). Mean \pm SEM normalized cued port-entries averaged across the final 2 days of training are shown in Figure 1f. In addition, ITI port-entries as a portion of total port-entries were higher on the first 3 days than the final 3 days of training (Figure $1 \mathrm{~g}$ ).

\section{Effect of AcbSh Inactivation on Non-Reinforced Cue- Triggered EtOH Seeking Across Contexts}

Previous studies suggest that AcbSh has an important role inhibiting non-reinforced behavior, and also mediating the ability for reward-paired cues to modulate behavior (Ambroggi et al, 2011; Shiflett and Balleine, 2010). Thus, we hypothesized that AcbSh inactivation might mitigate the impact of reward-associated cues while also disinhibiting behavior during omission of the cue (ITI). Our results confirmed this (Figure 2; N=10). There was significantly reduced cue behavior following AcbSh inactivation (Figure $2 \mathrm{a}$ and 2-a1). Cued port-entries were higher in the training than either neutral $\left(\mathrm{F}_{(1,9)}=10.35, p<0.05\right)$ or novel $\left(\mathrm{F}_{(1,9)}=8.64, p<0.05\right)$ contexts and associated contexttreatment interactions were significant $\left(F_{\text {-values }}(1,9)>6.30\right.$, $p$-values $<0.05)$, suggesting that inactivation impaired cuetriggered behavior in a context-dependent manner. Subsequent paired comparisons revealed a significant reduction in cued behavior following AcbSh inactivation in the training and novel contexts only $(\mathrm{F}$-values $(1,9)>8.36$, $p$-values $<0.05$; neutral context: $\left.F_{(1,9)}=3.25, p>0.05\right)$. This pattern of results was maintained when cue performance was examined in isolation from pre-CS values, suggesting that the attenuation of cued behavior following inactivation is independent of baseline responding (treatment: $\mathrm{F}_{(1,9)}=19.89, p<0.05$; treatment $\mathrm{x}$ context: $\mathrm{F}_{(1,9)}=6.24, p<0.05$ (training $v s$ neutral) and $\mathrm{F}_{(1,9)}=3.448, p>0.05$ (training $v s$ novel)). Conversely, AcbSh inactivation significantly elevated ITI behavior (Figure $2 \mathrm{~b}$ and 2-b1). This did not interact significantly with context (F-values $\left._{(1,9)}<1\right)$. Subsequent simple effects comparisons revealed a significant increase in ITI port-entries following AcbSh inactivation in the training $\left(\mathrm{F}_{(1,9)}=11.25, p=0.008\right)$ but not in neutral or novel contexts (F-values $_{(1,9)}<3.63$, $p$-values $>0.05)$. Finally, AcbSh inactivation did not significantly impact the total numbers of port-entries during test $($ F-values $(1,9)<2.47, p$-values $>0.05$; Figure $2 c)$. 
AcbSh a

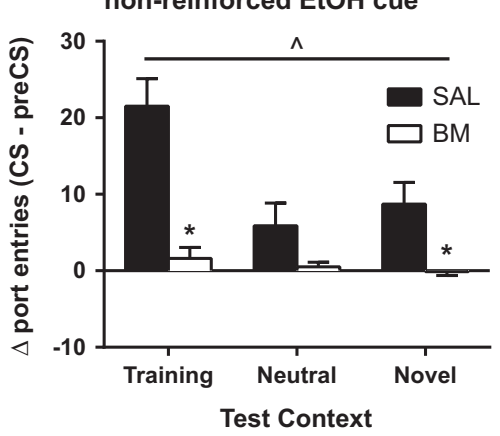

b

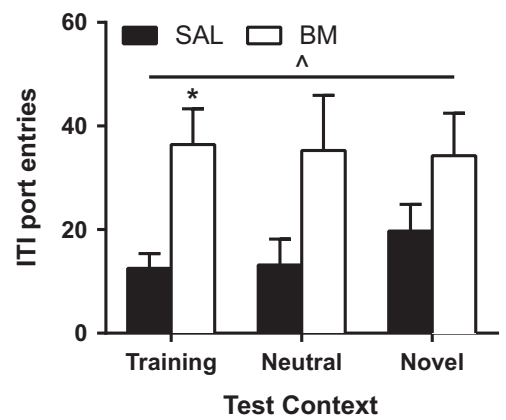

C

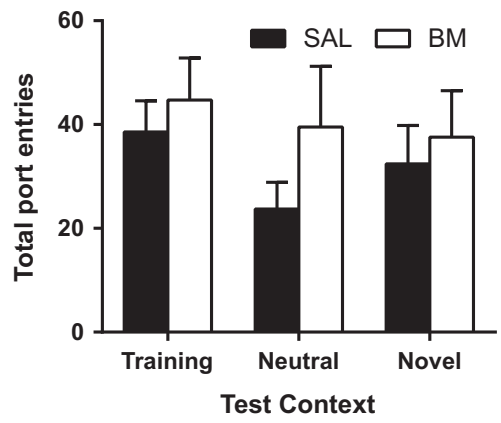

d

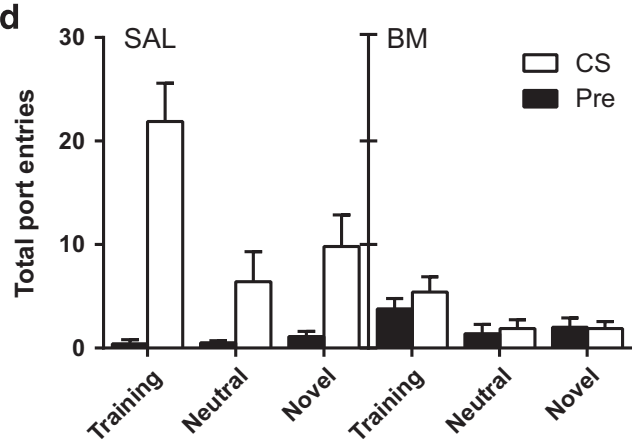

g e

Test:

reinforced EtOH cue

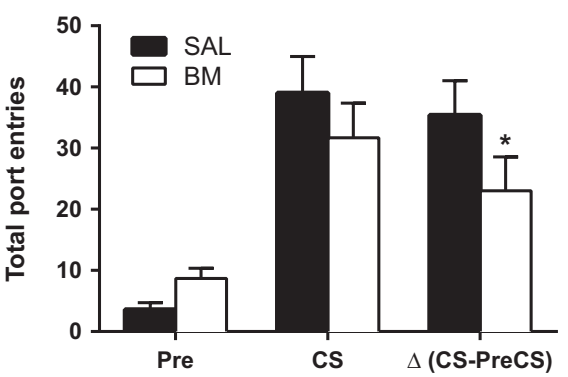

f

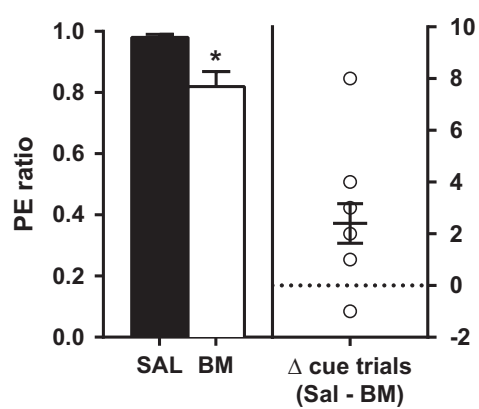

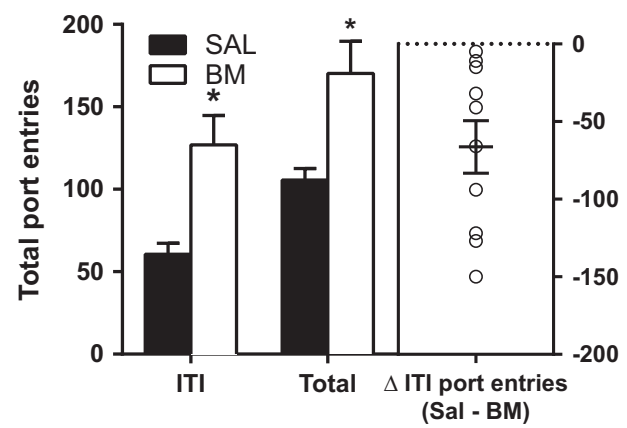

Figure 2 (a-d) Non-reinforced cue test following AcbSh inactivation. (a) Mean ( \pm SEM) numbers of normalized cue port-entries on test per context. ^Treatment main effect: $F_{(1,9)}=36.63, p<0.05$. (al) Panels here and in subsequent similar graphs shows difference scores for each subject per context; mean of difference scores and standard error of the difference (SED) are given as center-horizontal and vertical notch, respectively. (b) Mean ( \pm SEM) numbers of ITI port-entries on test. ^ Treatment main effect: $F_{(I, 9)}=7.27, p<0.05$. (b I) difference scores for each subject per context. (c) Mean ( \pm SEM) numbers of total port-entries on test per context. (d) Mean ( \pm SEM) numbers of port-entries on test under SAL (left panel) and BM (right panel) during I0-s precue and cue epoch per context. (e-g) Alcohol-reinforced test following AcbSh inactivation. (e) Mean ( \pm SEM) numbers of port-entries on test during pre-cue and cue epochs, and normalized number of cued port-entries. $(f)$ Mean $( \pm$ SEM) portion of test cue trials associated with port-entry (left panel) and difference scores for each subject (right panel). (g) Mean $( \pm$ SEM) numbers of ITI and total port-entries on test (left panel) and ITI difference scores for each subject. $* p<0.05$ simple effects comparisons (BM $\vee \mathrm{SAL})$ per context.

To assess the possibility that AcbSh inactivation interfered with modulation of behavior on test, we examined numbers of port-entries during the 10-s pre-CS epoch against the 10-s CS epoch, with mean ( \pm SEM) numbers shown in Figure $2 \mathrm{~d}$. Port-entries were significantly higher during the CS than pre-CS epoch $\left(\mathrm{F}_{(1,9)}=40.82, p<0.05\right)$ and following saline than BM infusions $\left(\mathrm{F}_{(1,9)}=8.9, p<0.05\right)$. Two-way epochtreatment interaction was also significant $\left(\mathrm{F}_{(1,9)}=36.63\right.$, $p<0.05)$, suggesting that modulation of behavior was reduced following AcbSh inactivation. This was not due to a suppressive effect of the drug on behavior since, as noted earlier, ITI behavior was elevated following AcbSh inactivation.

\section{Effect of AcbSh Inactivation on Reinforced Cue- Triggered EtOH Seeking Across Contexts}

To further assess AcbSh contributions to alcohol cue behavior, rats were tested under reinforced cue presentations. Figure 2e shows mean $( \pm$ SEM) port-entries during preCS, CS, and normalized CS. Cued port-entries were not significantly affected by AcbSh inactivation $\left(\mathrm{F}_{(1,9)}=4.68\right.$, 
$p=0.059)$, although when normalized for pre-CS baseline, conditioned behavior was significantly reduced $\left(\mathrm{F}_{(1,9)}=\right.$ 14.32, $p<0.05)$, suggesting an elevated behavioral baseline. Conversely, AcbSh inactivation significantly reduced the number of cue trials associated with at least one port-entry (as a ratio of total cue trials: $F_{(1,9)}=9.89$, $p<0.05)$, shown in Figure 2f. We also examined portentries across test in the first $4 \mathrm{~s}$ of the cue, which corresponds with the interval immediately before EtOH delivery. We reasoned that port-entries in this interval might reflect pre-emptive conditioned behavior. The number of cues associated with port-entries before EtOH delivery was unaffected by AcbSh inactivation (normalized for trials attempted; $\mathrm{F}_{(1,9)}<1, p>0.05$, not shown). Similarly, latency to respond to the cue was not significantly affected $\left(\mathrm{F}_{(1,9)}<1\right.$, $p>0.05$, not shown). Finally, since the first trial may be different to subsequent trials (ie, there is no previous information on the first trial to predict presence or absence of reinforcer on test), we inspected behavior during the first trial and found no significant effect of treatment $\left(\mathrm{F}_{(1,9)}<1\right.$, $p>0.05$, not shown). Finally, as shown in Figure $2 \mathrm{~g}$, ITI behavior $\left(\mathrm{F}_{(1,9)}=15.32, p<0.05\right)$ and total port-entries $\left(\mathrm{F}_{(1,9)}=13.98, p<0.05\right)$ were significantly elevated following AcbSh inactivation.

\section{Effect of Amygdala Inactivation on Non-Reinforced Cue-Triggered Alcohol Seeking Across Contexts}

The AcbSh receives significant yet topographically distributed projections from anterior BLA and posterior BAP. We hypothesized that these distinct nuclei may have dissociable contributions to cue-triggered $\mathrm{EtOH}$ seeking.

$B L A$. There was reduced cue behavior following BLA inactivation (Figure 3 and 3 -a1; $N=9$ ) main effect across contexts: $\left.\mathrm{F}_{(1,8)}=12.70, p<0.05\right)$. Cue-triggered behavior was greater in the training than neutral $\left(\mathrm{F}_{(1,8)}=14.63, p<0.05\right)$ context and this interacted significantly with treatment $\left(F_{(1,8)}=12.22, p<0.05\right)$. However, there were no significant differences on test between the training and novel context or corresponding treatment interactions $(\mathrm{F}$-values $(1,8)<1.46$, $P$-values $>0.05)$. Subsequent paired comparisons revealed a significant reduction in cued behavior following BLA inactivation in the training $\left(\mathrm{F}_{(1,8)}=14.69, p<0.05\right)$ and novel $\left(\mathrm{F}_{(1,8)}=7.93, p<0.05\right)$ contexts, but not in the neutral context $\left(\mathrm{F}_{(1,8)}=4.26, p>0.05\right)$. Moreover, there was no effect of BLA inactivation on ITI port-entries (Figure $3 \mathrm{~b}$ and 3-b1; F-values $_{(1,8)}<3.01, \quad p$-values $\left.>0.05\right)$. Subsequent paired comparisons revealed a significant reduction in ITI behavior following BLA inactivation in the training context $\left(\mathrm{F}_{(1,8)}=5.93, p=0.041\right)$ but not others $\left(\mathrm{F}_{-v^{-}}\right.$alues $\left.(1,8)<1\right)$. Finally, total numbers of port-entries across test were reduced following BLA inactivation (Figure 3c), and this effect was greatest in the training than in the neutral context $\left(F_{(1,8)}=19.48, p<0.05\right)$. There were no significant differences between the training and novel contexts or corresponding treatment interactions (F-values $(1,8)<4.30, P$-values $>0.05$ ). Subsequent paired comparisons revealed a significant effect of BLA inactivation on total port-entries in the training and novel contexts $\left(\mathrm{F}_{\text {-values }}(1,8)>11.25, P\right.$-values $\left.<0.05\right)$ but not in the neutral context $\left(\mathrm{F}_{(1,8)}<1.41, p>0.05\right)$.
$B A P$. Our results confirmed a dissociable role for posterior amygdala (Figure $4 ; N=8$ ). There was reduced cue behavior (normalized) following BAP inactivation. Cued port-entries were greater in the training than either neutral $\left(\mathrm{F}_{(1,7)}=12.67\right.$, $p<0.05)$ or novel $\left(\mathrm{F}_{(1,7)}=11.08, p<0.05\right)$ contexts. However, BAP inactivation did not interact with context (F-value$\mathrm{s}_{(1,7)}<1.32, P$-values $\left.>0.05\right)$. Subsequent paired comparisons were significant in the neutral context $\left(\mathrm{F}_{(1,7)}=5.57, p=0.05\right)$ and not the others $\left(F_{\text {-values }}(1,7)<3.12, P\right.$-values $\left.>0.05\right)$. This pattern of findings was maintained when cue performance was examined in isolation from pre-CS values (treatment: $\mathrm{F}_{(1,7)}=6.27, p<0.05$; context: F-values $_{(1,9)}>9.83$, $P$-value$\mathrm{s}<0.05$; context-treatment: F-values $_{(1,9)}<1.35, \quad P$-values $>0.05)$. This suggests that attenuation of cued behavior following BAP inactivation is independent of elevated baseline responding. Conversely, BAP inactivation elevated ITI behavior (Figure $4 \mathrm{~b}$ and 4-b1) and this effect did not interact with context $\left(F_{\text {-values }}(1,7)<2.25, P\right.$-values $\left.>0.05\right)$. Subsequent paired comparisons revealed elevated ITI behavior in the training $\left(\mathrm{F}_{(1,7)}=8.60, p<0.05\right)$ and novel $\left(\mathrm{F}_{(1,7)}=8.32, p<0.05\right)$, but not neutral context $\left(\mathrm{F}_{(1,7)}=3.84\right.$, $p>0.05)$.

As BAP inactivation impaired behavior similarly to AcbSh inactivation, we assessed whether BAP inactivation would disrupt behavior modulation on test. As shown in Figure 4d, port-entries were significantly higher during the CS than pre-CS epoch $\left(\mathrm{F}_{(1,7)}=25.59, p<0.05\right)$. Although there was no main effect of treatment $\left(\mathrm{F}_{(1,7)}=5.27, p=0.055\right)$, a two-way epoch-treatment interaction was significant $\left(\mathrm{F}_{(1,7)}=7.35\right.$, $p<0.05)$, suggesting that BAP inactivation reduced the rise in port-entries during the cue relative to pre-cue baseline. Together, these findings suggest that BAP inactivation prevented the behavioral impact of the EtOH cue independent of context. Moreover, it demonstrates that, like AcbSh, BAP inactivation differentially affects conditioned and unconditioned port-entries.

\section{Effect of BAP Inactivation on Reinforced EtOH Seeking Across Contexts}

As BAP inactivation produced similar disruptions in behavior as AcbSh inactivation, we conducted subsequent tests under reinforced cue presentations to further assess this functional overlap. Total port-entries made during the preCS, CS, or normalized cued port-entries were not significantly affected by BAP inactivation $\left(\right.$ F-values $_{(1,7)}<1$; Figure 4e). There was no significant effect of BAP inactivation on cue trials associated with at least one portentry (ratio of total cue trials: $F_{(1,7)}=2.36, p>0.05$; Figure $4 \mathrm{f}$ ) or pre-emptive conditioned port-entries, defined as those occurring in the first $4 \mathrm{~s}$ of the cue $\left(\mathrm{F}_{(1,7)}=4.573, p=0.07\right.$, not shown). Finally, as shown in Figure $4 \mathrm{~g}$, ITI $\left(\mathrm{F}_{(1,7)}=5.56\right.$, $p=0.05)$ but not total port-entries $\left(\mathrm{F}_{(1,7)}=3.44, p>0.05\right)$ was significantly elevated. Together, our findings suggest that BLA and BAP differentially mediate conditioned behavior, and that the profile of behavior following BAP inactivation is largely similar to AcbSh inactivation.

\section{Excluded Rats}

We analyzed data from all seven animals with misplaced and thus peri-BAP injections. Included were three animals with 


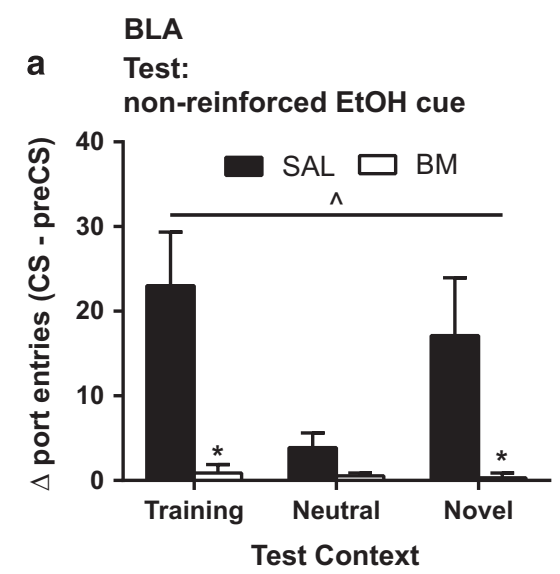

b
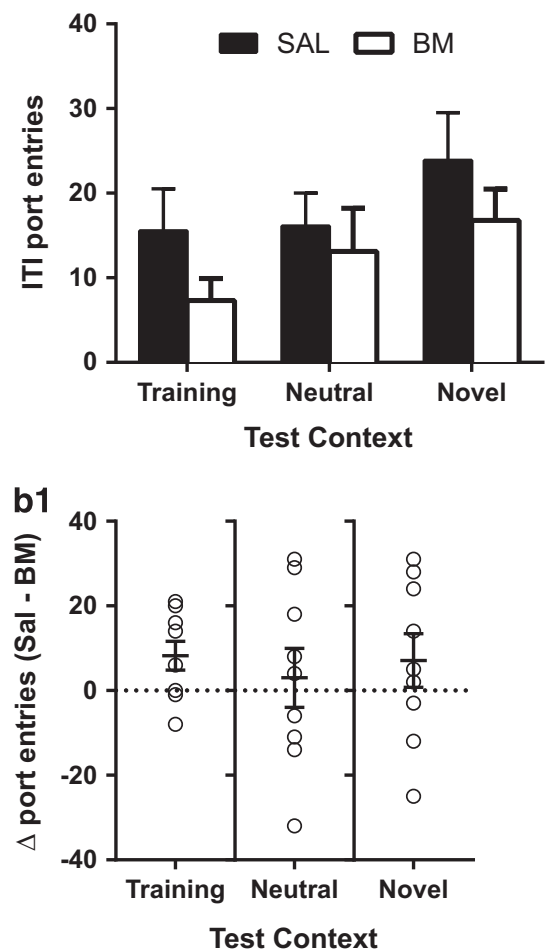

C

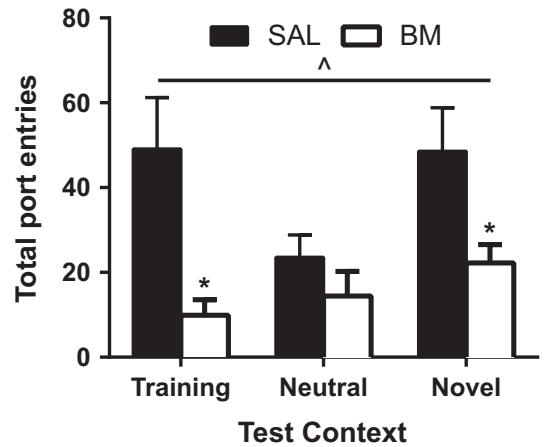

c1

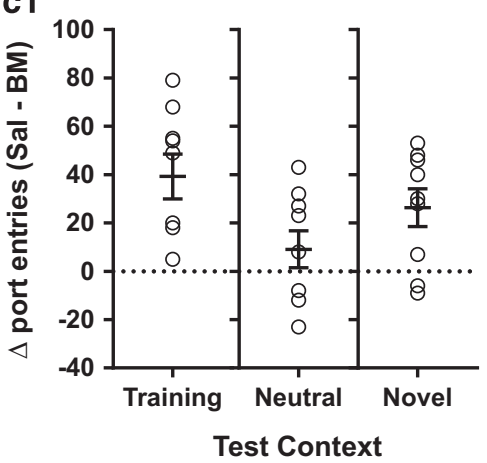

Figure 3 Non-reinforced test following BLA inactivation. Mean $( \pm \mathrm{SEM})$ numbers for (a) normalized cued port-entries; ${ }^{\text {treatment }}$ main effect: $F_{(1,9)}=36.63, p<0.05$. (b) ITI port-entries and (c) total port-entries per context; ${ }^{\prime}$ treatment main effect: $F_{(1,8)}=\mid 1.39, p<0.05$. Difference scores for each subject for normalized cued-, ITI-, and total port-entries are shown in (al, bl, and cl) respectively. ${ }^{*} p<0.05$ simple effects comparisons (BM $\left.\vee \mathrm{SAL}\right)$ per context.

injection tracts bilaterally within the lateral ventricles. As shown in Figure 5a and b, there was no significant effect of peri-BAP inactivation on cue behavior in a non-reinforced cue test (normalized: $\mathrm{F}_{(1,6)}=5.68, p=0.06$; context-treatment interactions: F-values $_{(1,6)}<2.07, p$-values $>0.05$; paired comparisons: $F$-values $_{(1,6)}<4.83$, $p$-values $\left.>0.05\right)$. Moreover, there was no significant effect of peri-BAP inactivation on ITI behavior $\left(F_{(1,6)}=1.77, p>0.05\right.$; context-treatment interactions: F-values $_{(1,6)}<3.83, \quad p$-values $>0.05$; paired comparisons: F-values $(1,6)<2.94, p$-values $>0.05)$ or under reinforced test conditions (normalized cue and ITI: F-values $\left._{(1,6)}<1\right)$.

\section{DISCUSSION}

This study demonstrates that AcbSh and BAP inactivation prevent expression of alcohol cue-conditioned behavior, and simultaneously, augment unconditioned behavior occurring in the absence of the cue. In contrast, anterior BLA inactivation attenuated cue-conditioned behavior specifically. Together our data demonstrate for the first time an overlapping role for AcbSh and BAP in inhibiting behavior outside of the occurrence of alcohol-predictive cues, and provide evidence for dissociable roles for rostral and posterior portions of basal amygdala in the control over responses that surround these cues. These findings add to the relatively sparse literature on the behavioral role of posterior $\mathrm{BA}$ in alcohol and reward behavior. Moreover, using a discriminative context paradigm wherein cue-triggered performance is modulated by the presence of the original training context, we show that AcbSh inactivation mitigated conditioned behavior even in an environment not previously associated with alcohol. This unexpected finding extends our understanding of the behavioral influence of AcbSh in light of previous studies, suggesting a role for this region in the context-specific control over behavior (Chaudhri et al, 2010; Cruz et al, 2014; Ito et al, 2008; Lansink et al, 2012).

\section{AcbSh Inactivation Removes the Behavioral Impact of Pavlovian Alcohol Cues and Contexts}

The AcbSh has been considered to play an important role integrating the salience of environmental contexts and stimuli with their associated rewards and subsequent behavior (Kelley, 2004; Mogenson et al, 1980). Consistent with previous work demonstrating that AcbSh is necessary for Pavlovian cue-directed behavior and that neurons in this region encode Pavlovian conditioned cues (Blaiss and Janak, 2009; Corbit et al, 2001; Saddoris and Carelli, 2014; Shiflett and Balleine, 2010), here we found that alcohol-associated cues failed to prompt conditioned port-entry behaviors following AcbSh inactivation; importantly, this was regardless of the associative history of the context with alcohol. In contrast, using a renewal procedure involving alcoholreinforced cues, previous work from our laboratory found that AcbSh inactivation prevented cue-conditioned behavior 


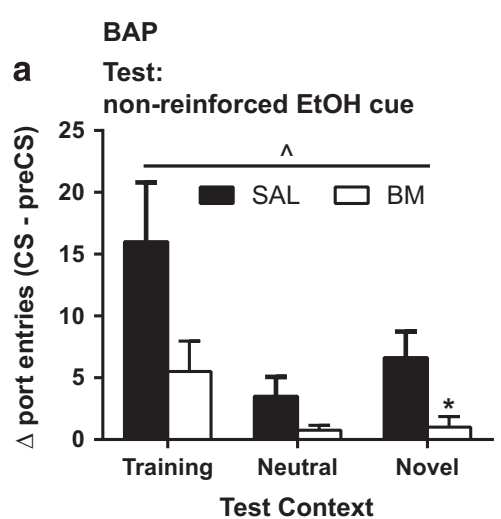

b
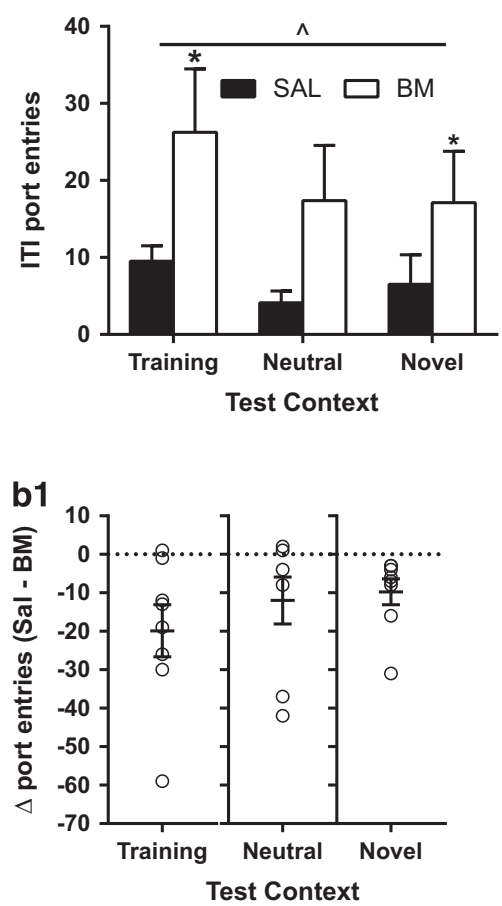

f

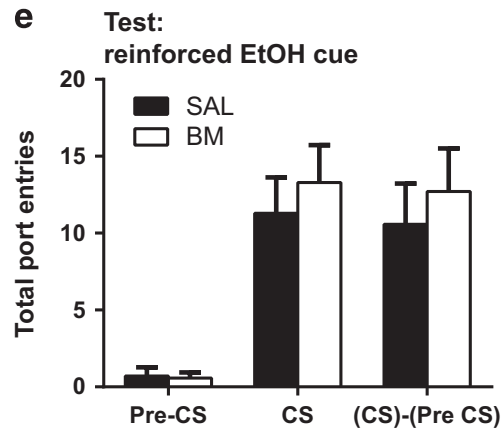

C

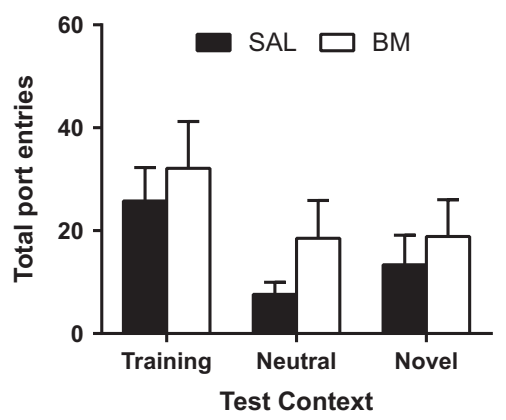

d

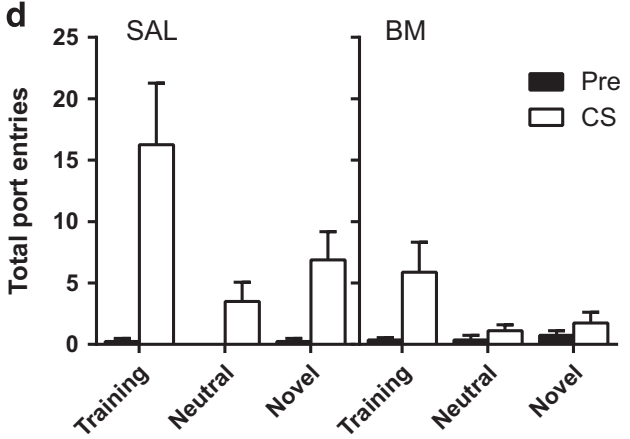

g

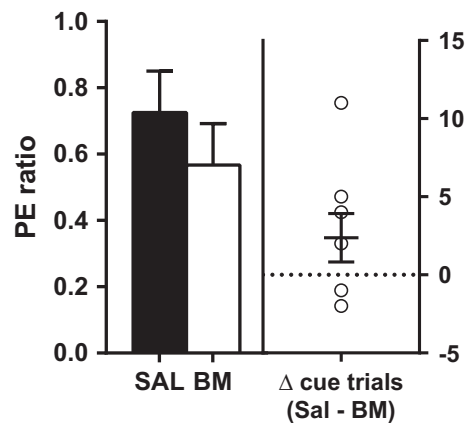

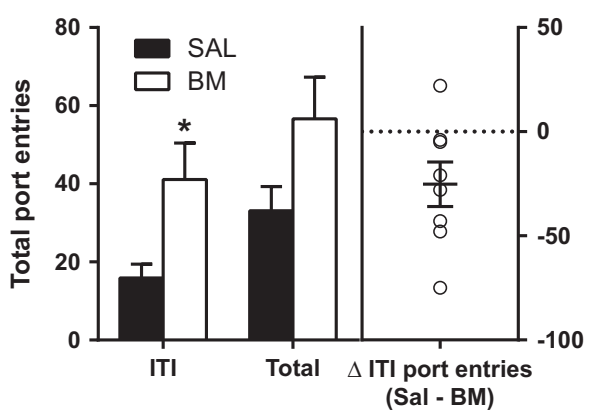

Figure 4 (a-d) Non-reinforced test following BAP inactivation. (a) Mean ( \pm SEM) numbers of normalized cue port-entries on test per context. ^ Treatment main effect: $F_{(I, 7)}=7.35, p<0.05$. (al) difference scores for each subject per context. (b) Mean ( \pm SEM) numbers of ITI port-entries on test. ^ Treatment main effect: $F_{(I, 7)}=10.43, p<0.05$. (b I) difference scores for each subject per context. (c) Mean ( \pm SEM) numbers of total port-entries on test per context. (d) Mean $( \pm$ SEM) numbers of port-entries on test under SAL (left panel) and BM (right panel) during I 0 s precue and cue epoch per context. (e-g) Alcohol-reinforced test following BAP inactivation. (e) Mean ( \pm SEM) numbers of port-entries on test during pre-cue and cue epochs, and normalized number of cued port-entries. (f) Mean $( \pm$ SEM) portion of test cue trials associated with port-entry (left panel) and difference scores for each subject (right panel). ( $g$ ) Mean ( \pm SEM) numbers of ITI and total port-entries on test (left panel) and ITI difference scores for each subject. $* p<0.05$ simple effects comparisons (BM vs SAL) per context.

specifically in an alcohol-paired context (Chaudhri et al, 2010). Consistent with this, AcbSh inactivation prevented cue-conditioned behavior in the alcohol training-context and not in the neutral-context; however, we also show that AcbSh inactivation can impair conditioned behavior when tested in a novel context. This suggests that, although AcbSh may be involved in many context-dependent tasks (Chaudhri et al, 2010; Cruz et al, 2014; Ito et al, 2008; Lansink et al, 2012), additional stimulation, such as that driven by a novel context, may be an important factor for detecting or recruiting AcbSh-dependent control over behavior. This may be the case in the present study where low levels of conditioned behavior in the neutral context may have occluded the effects of AcbSh inactivation. Moreover, as
AcbSh inactivation appeared to disrupt the topography of behavior surrounding the cue, ie, it did not reliably alter the total number of responses during a nonreinforced test but instead promoted behavior during the absence of the cue and prevented behavior during the presence of the cue, our data suggest that the disruption of conditioned behavior following AcbSh inactivation may be, at least in part, due to a disruption in cues biasing behavior.

The behavioral processes through which this might be achieved remain unclear. One possibility is that AcbSh inactivation disinhibits otherwise competing behaviors, which may, in turn, mask the learned motivational significance of alcohol-associated cues and contexts. Indeed, Pavlovian conditioning has been proposed to organize natural behavioral 

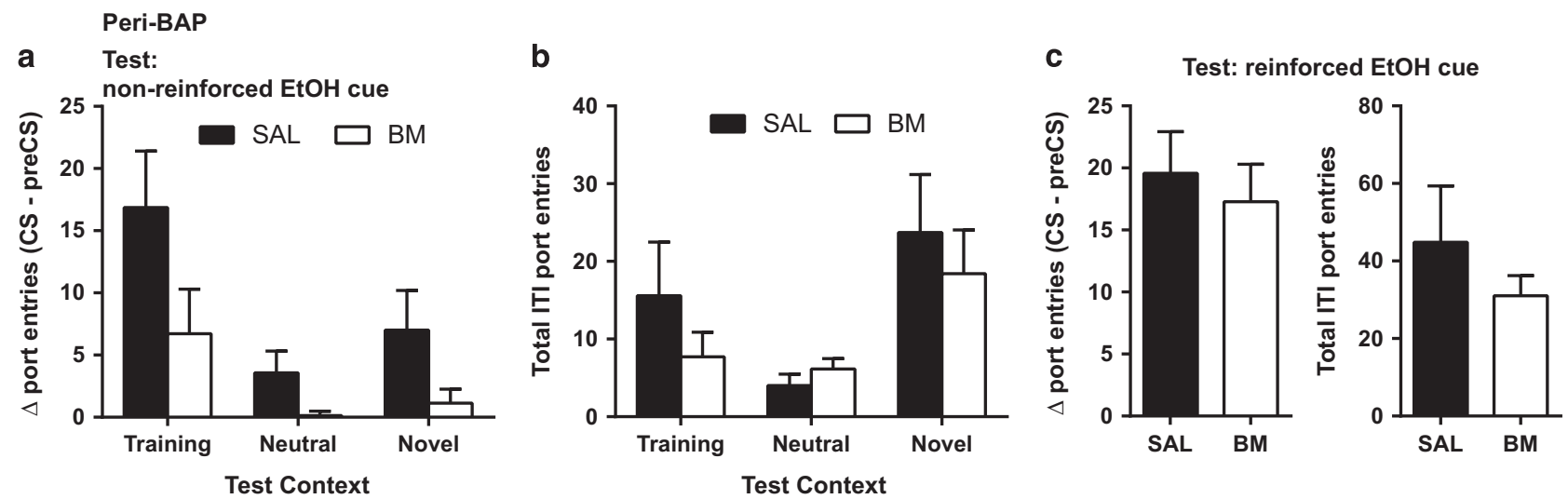

Figure 5 ( $a, b)$ Non-reinforced test following peri-BAP inactivation. (a) Mean ( \pm SEM) numbers of normalized cue port-entries per context and (b) ITI port-entries on test. (c) Alcohol-reinforced test following peri-BAP inactivation. Mean ( \pm SEM) numbers of normalized cue port-entries (left panel) and ITI port-entries on test (right panel).

sequences (Timberlake, 1994), and this organization may involve suppression of competing behaviors to enable successful expression of conditioned behavior. For example, focal search behaviors may be prioritized at the time of the cue, whereas more general search behaviors occur outside of the cue, and appropriate variation between these two strategies may be important for Pavlovian conditioned appetitive behavior. Consistent with this, we detected a reduction in unconditioned ITI behavior on the final days of training relative to the commencement of training that coincided with an increase in cue-triggered behavior across training days. Moreover, in vivo electrophysiology studies have shown that port-entry behavior in appetitive tasks can correspond with distinct neuronal activity depending on whether port-entries were made during or outside of a reward cue (Lansink et al, 2012; Tye and Janak, 2007), suggesting that cue-triggered and ITI port-entries may be qualitatively distinct behaviors.

Although the experiments here focused on AcbSh, previous work has shown that AcbSh and nucleus accumbens core (AcbC) inactivation can similarly prevent the performance of Pavlovian conditioned behavior (Blaiss and Janak, 2009; Chaudhri et al, 2010). Nonetheless, it is possible that there may be some diffusion of baclofen/muscimol from AcbSh to AcbC, although some degree of functional overlap between these two regions may be expected and further studies will be needed to characterize their functional distinctions.

\section{Differential Contributions of Basal Amygdala Nuclei on Conditioned Behavior}

Functional distinctions between rostral and caudal BLA have been reported previously in instrumental-trained animals (Kantak et al, 2002; McLaughlin and Floresco, 2007), although they are few. In one study, pharmacological inactivation of caudal BLA was reported to potentiate cueinduced reinstatement of an extinguished lever-pressing response, whereas rostral BLA inactivation had no effect (McLaughlin and Floresco, 2007). Here, using a Pavlovian conditioning preparation, we similarly detected functional dissociations between these regions. Rostral BLA inactivation impaired conditioned responding independent of the training context in which cue-alcohol associations were acquired, but did not alter behavior outside of the cue. Conversely, BAP inactivation produced elevated behavior during the ITI and a reduction of conditioned behavior. This elevation in ITI behavior is consistent with previous reports of impaired extinction or potentiated reinstatement following inactivation of the caudal BLA (McLaughlin and Floresco, 2007) or lesions of the BLA that encompass caudal BLA regions (Lindgren et al, 2003). Moreover, in vivo electrophysiology studies support the presence of neurons that encode reward omission following the extinction of operant responding (Tye et al, 2010), and notably, electrode recording tips in this study were well-distributed in posterior as well as anterior regions of basal amygdala.

Interestingly, the effects of BAP and AcbSh inactivation were distinct when tested under reinforced conditions. That is, BAP inactivation failed to disrupt conditioned behavior when EtOH was present (reinforced test). AcbSh inactivation decreased the probability of port-entries occurring at the time of the cue, although other measures of conditioned responding were not significantly altered. Thus, unlike BAP, we detected some disruption of behavior following AcbSh inactivation under EtOH-reinforced test conditions, highlighting the notion that AcbSh inactivation will affect both BAP-related and non-BAP-related neuronal activity.

A technical limitation of targeting the BAP is that the lateral ventricles, which are increasingly enlarged caudally, are adjacent to the BAP. In an attempt to address this, we analyzed the behavioral data from a separate group of animals that received misplaced cannulae, including those with cannulae terminating bilaterally into the lateral ventricles. Although there was considerable variability in the expression of conditioned behavior following peri-BAP inactivation in the non-reinforced test, there was no effect of peri-BAP inactivation on ITI behavior across non-reinforced and reinforced tests. This suggests that the effects of BAP inactivation on uncued behavior are regionally specific. In addition, it is worth noting that, at the posterior end of the amygdala, basomedial and basolateral amygdala are difficult to isolate, as they are immediately adjacent and each are reduced in size relative to rostral levels. For this reason we have found it appropriate to describe the posterior area of interest as the posterior basal amygdala (BAP), as it likely includes medial and lateral portions of the basal amygdala. 


\section{Basal Amygdala Inputs are Topographically Organized within AcbSh}

The Acb receives robust and topographically organized projections from amygdala. Specifically, BAP targets the dorsomedial tip of the AcbSh, whereas rostral BLA preferentially targets both core and ventromedial AcbSh regions (Canteras et al, 1992; Thompson and Swanson, 2010). This anatomical segregation within AcbSh was a primary motivation to separately examine anterior BLA and BAP. Importantly, AcbSh inactivation likely removes the influence of both amygdala inputs, as well as other inputs into the AcbSh, and circuit-specific approaches will be necessary to isolate possible BLA-AcbSh and BAP-AcbSh contributions to behavior. Beyond their connectivity with the AcbSh, these amygdala regions are segregated in their anatomically organization in relation to downstream hypothalamus (Petrovich et al, 2001) and prefrontal cortex (Canteras et al, 1992; Mcdonald, 1991; Shinonaga et al, 1994). Thus, AcbSh may be strategically situated to integrate information from these two amygdala systems, and perhaps prioritize the expression of competing behaviors driven by the presence and absence of important environmental stimuli.

Finally, an important consideration is that unlike many standard conditioning preparations that involve discrimination between reinforced and non-reinforced cues, animals here received only reinforced cues during training. The distinct absence of cue discrimination during the initial learning phase in these studies may affect what is learned about these cues and in turn, the neural systems that subsequently mediate conditioned behavior to alcohol cues. Nonetheless, the present findings suggest that AcbSh, BLA and BAP inactivation are each sufficient to disrupt cue-driven behavior acquired through simple non-discriminative cuereward learning.

\section{Concluding Remarks}

An inhibitory influence of AcbSh over behavior was documented in early studies of feeding (Stratford and Kelley, 1997) and has been thought to serve as an adaptive biological mechanism for overriding appetitive signals to quickly divert behavior in the presence of important environmental events (Kelley, 2004). The findings from the present study suggest that behavior maintained by Pavlovian conditioned alcohol cues may co-opt this AcbSh functionsuppressing unconditioned behavior to respond during an alcohol predictive cue. Importantly, our findings suggest that this role may be shared by BAP. These findings raise the possibility that afferents from rostral and posterior basal amygdala to AcbSh may have distinct circuit-specific behavioral consequences.

\section{FUNDING AND DISCLOSURE}

The authors declare no conflict of interest.

\section{ACKNOWLEDGMENTS}

This work was supported by NIAAA Grant AA014925.

\section{REFERENCES}

Ambroggi F, Ghazizadeh A, Nicola SM, Fields HL (2011). Roles of nucleus accumbens core and shell in incentive-cue responding and behavioral inhibition. J Neurosci 31: 6820-6830.

Blaiss CA, Janak PH (2009). The nucleus accumbens core and shell are critical for the expression, but not the consolidation, of Pavlovian conditioned approach. Behav Brain Res 200: 22-32.

Brog JS, Salyapongse A, Deutch AY, Zahm DS (1993). The patterns of afferent innervation of the core and shell in the 'accumbens' part of the rat ventral striatum: immunohistochemical detection of retrogradely transported fluoro-gold. J Comp Neurol 338: 255-278.

Canteras NS, Simerly RB, Swanson LW (1992). Connections of the posterior nucleus of the amygdala. J Comp Neurol 324: 143-179.

Chaudhri N, Sahuque LL, Schairer WW, Janak PH (2010). Separable roles of the nucleus accumbens core and shell in context- and cue-induced alcohol-seeking. Neuropsychopharmacology 35: 783-791.

Cho YT, Ernst M, Fudge JL (2013). Cortico-amygdala-striatal circuits are organized as hierarchical subsystems through the primate amygdala. J Neurosci 33: 14017-14030.

Corbit LH, Muir JL, Balleine BW (2001). The role of the nucleus accumbens in instrumental conditioning: evidence of a functional dissociation between accumbens core and shell. J Neurosci 21: 3251-3260.

Cruz FC, Babin KR, Leao RM, Goldart EM, Bossert JM, Shaham Y et al (2014). Role of nucleus accumbens shell neuronal ensembles in context-induced reinstatement of cocaine-seeking. J Neurosci 34: 7437-7446.

German PW, Fields HL (2007). Rat nucleus accumbens neurons persistently encode locations associated with morphine reward. J Neurophysiol 97: 2094-2106.

Ghazizadeh A, Ambroggi F, Odean N, Fields HL (2012). Prefrontal cortex mediates extinction of responding by two distinct neural mechanisms in accumbens shell. J Neurosci 32: 726-737.

Ito R, Robbins TW, Pennartz CM, Everitt BJ (2008). Functional interaction between the hippocampus and nucleus accumbens shell is necessary for the acquisition of appetitive spatial context conditioning. J Neurosci 28: 6950-6959.

Kantak KM, Black Y, Valencia E, Green-Jordan K, Eichenbaum HB (2002). Dissociable effects of lidocaine inactivation of the rostral and caudal basolateral amygdala on the maintenance and reinstatement of cocaine-seeking behavior in rats. J Neurosci 22: 1126-1136.

Kelley AE (2004). Ventral striatal control of appetitive motivation: role in ingestive behavior and reward-related learning. Neurosci Biobehav Rev 27: 765-776.

Krause M, German PW, Taha SA, Fields HL (2010). A pause in nucleus accumbens neuron firing is required to initiate and maintain feeding. J Neurosci 30: 4746-4756.

Lansink CS, Jackson JC, Lankelma JV, Ito R, Robbins TW, Everitt BJ et al (2012). Reward cues in space: commonalities and differences in neural coding by hippocampal and ventral striatal ensembles. J Neurosci 32: 12444-12459.

Lindgren JL, Gallagher M, Holland PC (2003). Lesions of basolateral amygdala impair extinction of CS motivational value, but not of explicit conditioned responses, in Pavlovian appetitive second-order conditioning. Eur J Neurosci 17: 160-166.

Marchant NJ, Hamlin AS, McNally GP (2009). Lateral hypothalamus is required for context-induced reinstatement of extinguished reward seeking. J Neurosci 29: 1331-1342.

McDonald AJ (1991). Topographical organization of amygdaloid projections to the caudatoputamen, nucleus accumbens, and related striatal-like areas of the rat brain. Neuroscience 44: 15-33.

Mcdonald AJ (1991). Organization of amygdaloid projections to the prefrontal cortex and associated striatum in the rat. Neuroscience 44: 1-14. 
McLaughlin RJ, Floresco SB (2007). The role of different subregions of the basolateral amygdala in cue-induced reinstatement and extinction of food-seeking behavior. Neuroscience 146: 1484-1494.

Millan EZ, Furlong TM, McNally GP (2010). Accumbens shellhypothalamus interactions mediate extinction of alcohol seeking. J Neurosci 30: 4626-4635.

Mogenson GJ, Jones DL, Yim CY (1980). From motivation to action: functional interface between the limbic system and the motor system. Prog Neurobiol 14: 69-97.

Peters J, LaLumiere RT, Kalivas PW (2008). Infralimbic prefrontal cortex is responsible for inhibiting cocaine seeking in extinguished rats. J Neurosci 28: 6046-6053.

Petrovich GD, Canteras NS, Swanson LW (2001). Combinatorial amygdalar inputs to hippocampal domains and hypothalamic behavior systems. Brain Res Rev 38: 247-289.

Remedios J, Woods C, Tardif C, Janak PH, Chaudhri N (2014). Pavlovian-conditioned alcohol-seeking behavior in rats is invigorated by the interaction between discrete and contextual alcohol cues: implications for relapse. Brain Behav 4: 278-289.

Roitman MF, Wheeler RA, Carelli RM (2005). Nucleus accumbens neurons are innately tuned for rewarding and aversive taste stimuli, encode their predictors, and are linked to motor output. Neuron 45: 587-597.

Saddoris MP, Carelli RM (2014). Cocaine self-administration abolishes associative neural encoding in the nucleus accumbens necessary for higher-order learning. Biol Psychiatr 75: 156-164.

Shiflett MW, Balleine BW (2010). At the limbic-motor interface: disconnection of basolateral amygdala from nucleus accumbens core and shell reveals dissociable components of incentive motivation: BLA-accumbens and motivation. Eur J Neurosci 32: $1735-1743$

Shinonaga Y, Takada M, Mizuno N (1994). Topographic organization of collateral projections from the basolateral amygdaloid nucleus to both the prefrontal cortex and nucleus accumbens in the rat. Neuroscience 58: 389-397.

Simms JA, Steensland P, Medina B, Abernathy KE, Chandler LJ, Wise $\mathrm{R}$ et al (2008). Intermittent access to $20 \%$ ethanol induces high ethanol consumption in Long-Evans and Wistar Rats. Alcohol Clin Exp Res 32: 1816-1823.

Stratford TR, Kelley AE (1997). GABA in the nucleus accumbens shell participates in the central regulation of feeding behavior. J Neurosci 17: 4434-4440.

Sutton MA, Schmidt EF, Choi K-H, Schad CA, Whisler K, Simmons D et al (2003). Extinction-induced upregulation in AMPA receptors reduces cocaine-seeking behaviour. Nature 421: 70-75.

Thompson RH, Swanson LW (2010). Hypothesis-driven structural connectivity analysis supports network over hierarchical model of brain architecture. Proc Natl Acad Sci 107: 15235-15239.

Timberlake W (1994). Behavior systems, associationism, and Pavlovian conditioning. Psychon Bull Rev 1: 405-420.

Tye KM, Cone JJ, Schairer WW, Janak PH (2010). Amygdala neural encoding of the absence of reward during extinction. J Neurosci 30: $116-125$.

Tye KM, Janak PH (2007). Amygdala neurons differentially encode motivation and reinforcement. J Neurosci 27: 3937-3945.

Vassoler FM, White SL, Hopkins TJ, Guercio LA, Espallergues J, Berton $\mathrm{O}$ et al (2013). Deep brain stimulation of the nucleus accumbens shell attenuates cocaine reinstatement through local and antidromic activation. J Neurosci 33: 14446-14454. 